\title{
Round-bale Feeder Design Affects Hay Waste and Economics During Horse Feeding
}

\author{
K. Martinson, J. Wilson, K. Cleary, W. Lazarus, W. Thomas, and M. Hathaway \\ University of Minnesota, St. Paul, MN
}

Many horse owners find round bales convenient, less labor intensive and more affordable than other hay types, but report an inability to control horse weight gain and excessive hay waste. The objectives of this research were to compare hay waste, hay intake and payback of nine round-bale feeders and a no-feeder control when used during horse feeding. Nine round-bale feeders were tested: Cinch Net, Cone, Covered Cradle, Hayhut, Hay Sleigh, Ring, Tombstone, Tombstone Saver and Waste Less. Each feeder design was placed on the ground in a dirt paddock. Five groups of 5 horses were fed in rotation for a 4 day period with each feeder. Every fourth day, groups of horses were rotated among paddocks and a new round bale was placed in each feeder. In the five paddocks used, 5 feeders were installed for days 1 through 20, and the remaining 4 feeders and nofeeder control were installed for days 21 through 40. Groups of horses were sequentially assigned to feeders using two $5 \times 5$ Latin Squares, the first for days 1 though 20, the second for days 21 through 40. Horse groups of similar age, weight, breed, and gender were formed from 25 Quarter Horse and Thoroughbred geldings and open mares (means: $11 \mathrm{yr} ; 541 \mathrm{~kg}$ of body weight). Hay on the ground surrounding the feeder was collected daily, dried and weighed. The total amount of hay removed around each feeder for a 4 day period was considered waste. Number of months for reduced feeder waste to repay feeder cost (payback) were calculated using hay valued at $\$ 100 /$ ton, and improved feeder efficiency over the control. Neither carryover nor period effects were significant, thus the two Latin Squares were combined. No injuries were observed from any feeder. Cosmetic rub marks along the sides of faces were observed on many horses feeding from the Waste Less feeder. Bales collapsed after 2 days in the Cinch Net and horses were able to stand and defecate on the remaining hay. As a result, leftover hay in the cinch net was wetter ( $29 \%$ moisture) than the control $(P<0.02)$. If not removed, hay would likely mold and become unpalatable. The Cinch Net should be used in combination with another feeder to eliminate horse access. Mean percent hay waste differed among feeders $(P<0.001)$ and was, in increasing order, Waste Less, $5 \%$; Cinch Net, 6\%; Hayhut, 9\%; Covered Cradle, 11\%; Tombstone Saver, 13\%; Tombstone, Cone, and Ring, 19\%; Hay Sleigh, $33 \%$; and no-feeder control, $57 \%$. Feeder design also affected payback $(P<0.01)$. The Cinch Net paid for itself in less than 1 month; Tombstone and Ring, 2 months; Hayhut and Tombstone Saver, 4 months; Hay Sleigh, 5 months; Waste Less, 8 months; Cone, 9 months; and Covered Cradle, 20 months. The use of a round-bale feeder is necessary to avoid excessive hay waste. Round-bale feeders reduced hay waste compared to not utilizing a feeder, and all repaid their cost within two years. This information can be used to aid horse owners in making informed decisions when determining hay needs and purchasing round-bale feeders.

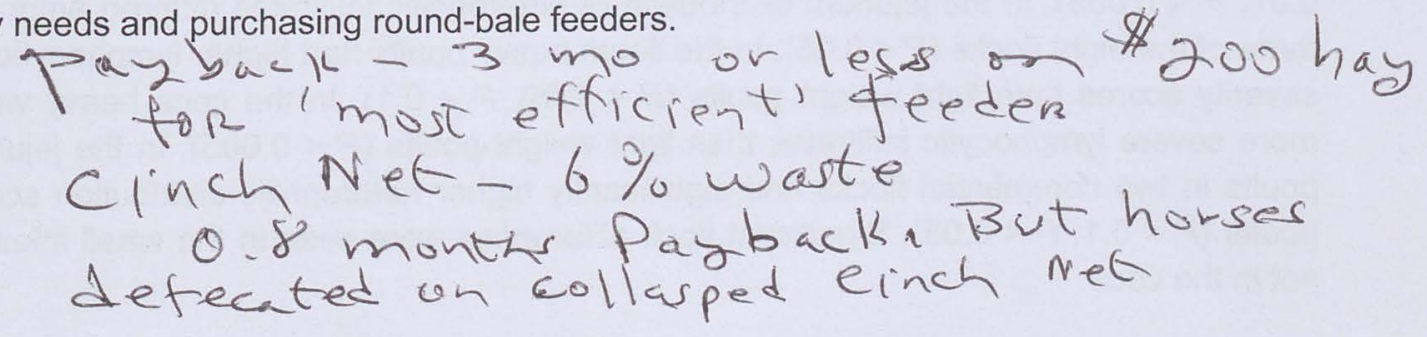

